\title{
Intestinal ABCA1 directly contributes to HDL biogenesis in vivo
}

\author{
Liam R. Brunham, ${ }^{1}$ Janine K. Kruit, ${ }^{2}$ Jahangir lqbal, ${ }^{3}$ Catherine Fievet, ${ }^{4}$ Jenelle M. Timmins, ${ }^{5}$ \\ Terry D. Pape, ${ }^{1}$ Bryan A. Coburn, ${ }^{6}$ Nagat Bissada, ${ }^{1}$ Bart Staels, ${ }^{4}$ Albert K. Groen, ${ }^{7}$ \\ M. Mahmood Hussain, ${ }^{3}$ John S. Parks, ${ }^{5}$ Folkert Kuipers, ${ }^{2}$ and Michael R. Hayden ${ }^{1}$
}

\begin{abstract}
${ }^{1}$ Centre for Molecular Medicine and Therapeutics, Child and Family Research Institute, Department of Medical Genetics, University of British Columbia, Vancouver, British Columbia, Canada. ${ }^{2}$ Center for Liver, Digestive and Metabolic Diseases, Laboratory of Pediatrics, University Medical Center Groningen, Groningen, The Netherlands. ${ }^{3}$ Department of Anatomy and Cell Biology, State University of New York Downstate Medical Center, New York, New York, USA. ${ }^{4}$ nstitut Pasteur de Lille and Faculté de Pharmacie, Université de Lille, Lille, France. ${ }^{5}$ Department of Pathology, Wake Forest University School of Medicine, Winston-Salem, North Carolina, USA. ${ }^{6}$ Department of Microbiology, University of British Columbia, Vancouver, British Columbia, Canada. ${ }^{7}$ Department of Experimental Hepatology, Academic Medical Center, Amsterdam, The Netherlands.
\end{abstract}

\begin{abstract}
Plasma HDL cholesterol levels are inversely related to risk for atherosclerosis. The ATP-binding cassette, subfamily $A$, member 1 (ABCA1) mediates the rate-controlling step in HDL particle formation, the assembly of free cholesterol and phospholipids with apoA-I. ABCA1 is expressed in many tissues; however, the physiological functions of ABCA1 in specific tissues and organs are still elusive. The liver is known to be the major source of plasma HDL, but it is likely that there are other important sites of HDL biogenesis. To assess the contribution of intestinal ABCA1 to plasma HDL levels in vivo, we generated mice that specifically lack ABCA1 in the intestine. Our results indicate that approximately $30 \%$ of the steady-state plasma HDL pool is contributed by intestinal ABCA1 in mice. In addition, our data suggest that HDL derived from intestinal ABCA1 is secreted directly into the circulation and that HDL in lymph is predominantly derived from the plasma compartment. These data establish a critical role for intestinal ABCA1 in plasma HDL biogenesis in vivo.
\end{abstract}

\section{Introduction}

HDL particles mediate the transport of cholesterol from peripheral tissues to the liver in a process termed reverse cholesterol transport $(1,2)$, which is postulated to explain, at least in part, their ability to protect against foam cell formation and atherosclerosis. Despite the widespread interest in HDL as a potential therapeutic target (3), the origins of plasma HDL are still elusive. The ATP-binding cassette, subfamily A, member 1 (ABCA1) mediates the rate-controlling step in HDL particle formation by promoting the efflux of cholesterol and phospholipids to apoA-I $(4,5)$. Mutations in ABCA1 cause Tangier disease (6-8), characterized by near absence of HDL cholesterol and increased risk for atherosclerosis $(9-11)$. ABCA1 is widely expressed throughout the body $(12,13)$; however, the contributions of ABCA1 in specific tissues to HDL levels and reverse cholesterol transport are still being unraveled, and only recently the role of hepatic ABCA1 in homeostasis of HDL levels was elucidated.

Overexpression of hepatic ABCA1 raises HDLcholesterollevels $(14,15)$, and liver-specific deletion of ABCA1 results in a substantial ( $~ 80 \%)$ decrease in plasma HDL cholesterol in chow-fed mice (16). Similarly, a 50\% knockdown of hepatic ABCA1 expression by adenovirus-mediated RNA interference in mice is associated with a $40 \%$ decrease in HDL cholesterol (17). These results indicate that the liver is the single most important source of plasma HDL in vivo but also suggest the existence of additional, extrahepatic sites of HDL biogenesis.

The intestine, along with the liver, is an important site for the synthesis and secretion of apoA-I, the principal apoprotein of HDL,

Nonstandard abbreviations used: ABCA1, ATP-binding cassette, subfamily A, member 1; FPLC, fast protein liquid chromatography.

Conflict of interest: The authors have declared that no conflict of interest exists. Citation for this article: J. Clin. Invest. 116:1052-1062 (2006). doi:10.1172/JCI27352. and contributes approximately $50 \%$ of total plasma apoA-I (18). In humans, approximately $1.5 \mathrm{~g}$ of dietary and biliary cholesterol enters the intestinal lumen each day (19). Cholesterol that is absorbed or synthesized locally in the enterocytes $(20)$ is thought to be either expelled into the intestinal lumen through the actions of the ABCG5/ABCG8 heterodimeric transporter for eventual excretion via the feces (21), or esterified by the action of ACAT and packaged into chylomicrons and VLDL particles for transport into the body (22). Cholesterol transport from the intestine is thought to occur almost exclusively by the lymphatic system (23).

A potential role for the intestine in HDL particle assembly was initially inferred from studies in hepatectomized dogs (24) and studies describing the presence of HDL of distinct composition and morphology in mesenteric lymph of rats (25-28). More recent studies in cultured cells have identified an apoBindependent pathway of cholesterol secretion from intestinal epithelial cells (29-31). However, the physiological contribution of the intestine to HDL levels is unknown, and the molecular mechanisms involved in intestinal HDL assembly are obscure. In addition, the origin of mesenteric lymph HDL has been a subject of considerable controversy (32-36), raising the question of whether HDL in mesenteric lymph is in fact derived from the intestine.

To specifically assess the role of intestinal ABCA1 in HDL metabolism in vivo, we have generated mice that lack ABCA1 exclusively in the intestine $\left(A b c a 1^{-i /-i}\right.$ mice). Our results show that intestinal ABCA1 is importantly involved in HDL biogenesis and contributes approximately $30 \%$ to steady-state plasma HDL cholesterol levels in mice. Furthermore, our data suggest that intestinal ABCA1 participates in HDL assembly via a direct mechanism into the circulation. 


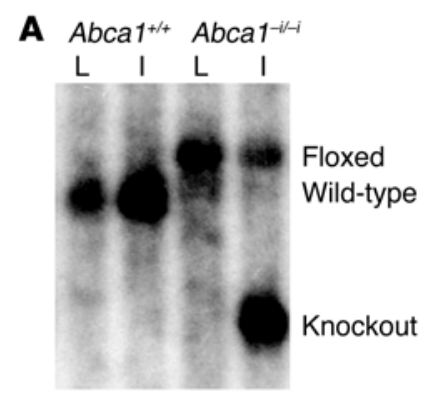

B

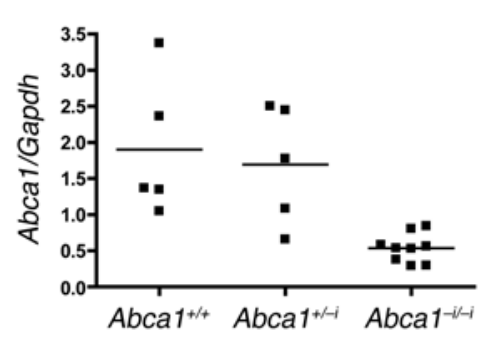

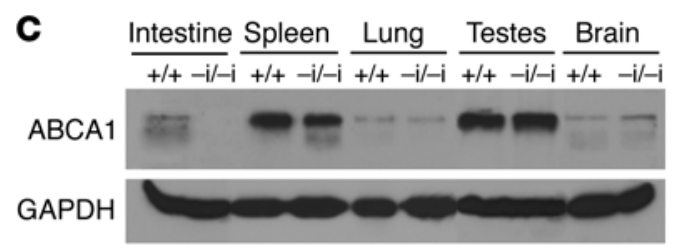

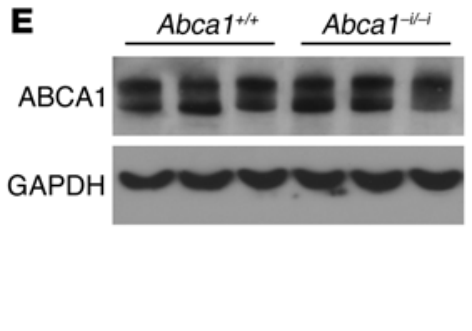

Figure 1

Generation of ABCA1 intestine-specific knockout mice $\left(A b c a 1^{-i /-i}\right)$. (A) Southern blot of genomic liver (L) and intestine (I) DNA from mice with WT $(+/+)$ or floxed $(-\mathrm{i} /-\mathrm{i})$ alleles in the presence of Cre recombinase. DNA was digested with EcoRV and hybridized with a probe to the genomic region between exons 44 and 45 in the Abca1 gene to produce the 6-kb WT, 7.3-kb floxed, and 4.2-kb knockout bands. (B) Quantitative real-time PCR of RNA isolated from mouse intestine. Reverse-transcribed RNA was amplified with oligos specific for Abca1 and Gapdh. (C) Western blot of tissue lysates from control (+/+) and $A b c a 1^{-i /-i}(-\mathrm{i} /-\mathrm{i})$ mice with antibodies against ABCA1, and GAPDH as loading control. (D) Quantitative real-time PCR of RNA isolated from livers of $A b c a 1^{+/+}$and $A b c a 1^{-i /-i}$ mice. Reverse-transcribed RNA was amplified with oligos specific for $A b c a 1$ and Actin. (E) Representative Western blot of liver lysates from $A b c a 1^{+/+}$and $A b c a 1^{-i /-i}$ mice.

\section{Results}

To evaluate the role of intestinal ABCA1 in HDL biogenesis in vivo, we generated mice that specifically lack ABCA1 in enterocytes by crossing Abca1 floxed mice (16) with mice expressing Cre recombinase under the control of the intestinal epithelium-specific Villin promoter (37). The Villin promoter drives robust expression of Cre through the length of the small and large intestine from $12.5 \mathrm{dpc}$ (37). Abca $1^{-i /-i}$ mice were born at the expected Mendelian frequencies, were fertile, and did not differ significantly in weight from littermate controls. Figure 1A shows Southern blot analysis of EcoRVdigested genomic DNA from livers and intestines of $\mathrm{Abca1}^{+/+}$and $A b c a 1^{-i /-i}$ littermates probed with a DNA fragment corresponding to intron 44. Cre-mediated deletion of $A b c a 1$ was evident in the intestine of $A b c a 1^{-i /-i}$ mice, but not in the liver of these mice, or in the intestine or liver of $A b c a 1^{+/+}$controls (Figure 1A).

Recombination of the floxed $A b c a 1$ allele resulted in a significant decrease in intestinal ABCA1 mRNA (Figure 1B) and protein levels (Figure $1 \mathrm{C})$. ABCA1 protein expression in other tissues was unaltered (Figure $1 C$ ), indicating that $A b c a 1^{-i /-i}$ mice specifically lack ABCA1 in the intestine.

Hepatic ABCA1 levels are a critical determinant of plasma HDL cholesterol concentration (16). Figure 1D shows hepatic Abca1 mRNA levels as determined by quantitative real-time PCR, revealing no alteration in expression of hepatic ABCA1 in $A b c a 1^{-i /-i}$ mice compared with controls. Figure $1 \mathrm{E}$ shows a representative immunoblot of liver lysates from $A b c a 1^{-i /-i}$ mice and controls, indicating that hepatic $\mathrm{ABCA} 1$ protein expression was normal. Therefore, hepatic ABCA1 levels are unaltered by deletion of intestinal ABCA1 and do not exhibit compensatory changes.

Figure 2 shows ABCA1 expression in mouse small intestine as detected by immunofluorescence. Ten-micron sections of fixed mouse intestine were stained with a polyclonal antibody against ABCA1 (12) (green), and counterstained with DAPI for cell nuclei (blue). ABCA1 protein was found to be highly expressed in enterocytes of the ileum (Figure 2, A-C) and jejunum (Figure 2D). ABCA1 expression was primarily observed in the intestinal villi, with less expression in crypts, consistent with a role in the absorptive regions of the intestine. ABCA1 expression was not detectable in the duodenum, cecum, or colon of WT mice (data not shown). ABCA1 appeared to be present both intracellularly and at the plasma membrane, including the basolateral membrane (Figure 2D), consistent with previous reports of $A B C A 1$ localization $(38,39)$. Abca $1^{-i /-i}$ mice had undetectable $A B C A 1$ protein expression in all sections analyzed (Figure 2, E-G), indicating complete ablation of $\mathrm{ABCA} 1$ protein expression in these mice. Figure $2 \mathrm{H}$ shows a section of WT jejunum stained with a random IgG to control for nonspecific staining.

Fasting plasma lipid and apolipoprotein concentrations in $A b c a 1^{+/+}, A b c a 1^{+/-i}$, and $A b c a 1^{-i /-i}$ mice are shown in Table 1. Total plasma cholesterol was significantly reduced by approximately $30 \%$ in $A b c a 1^{-i /-i}$ compared with $A b c a 1^{+/+}$mice, primarily because of a significant reduction in plasma HDL cholesterol $(-30 \%$, $P<0.001)$. Plasma levels of apoA-I and apoA-II were significantly decreased by approximately $25 \%$ and $35 \%$, respectively $(P \leq 0.05$; Table 1). Plasma apoB was also significantly reduced in $A b c a 1^{-i /-i}$ mice compared with controls by approximately $30 \%(P<0.01$; Table 1$)$. Notably, a gene-dosage effect was evident, with $A b c a 1^{+/-i}$ heterozygotes showing total plasma cholesterol and HDL cholesterol levels intermediate between those of WT and knockout mice and significantly reduced compared with those of WT mice $(P<0.05$; Table 1). Plasma apoA-I concentrations in $A b c a 1^{+/-i}$ heterozygotes tended to be reduced compared with those in controls, but this difference was not statistically significant. 

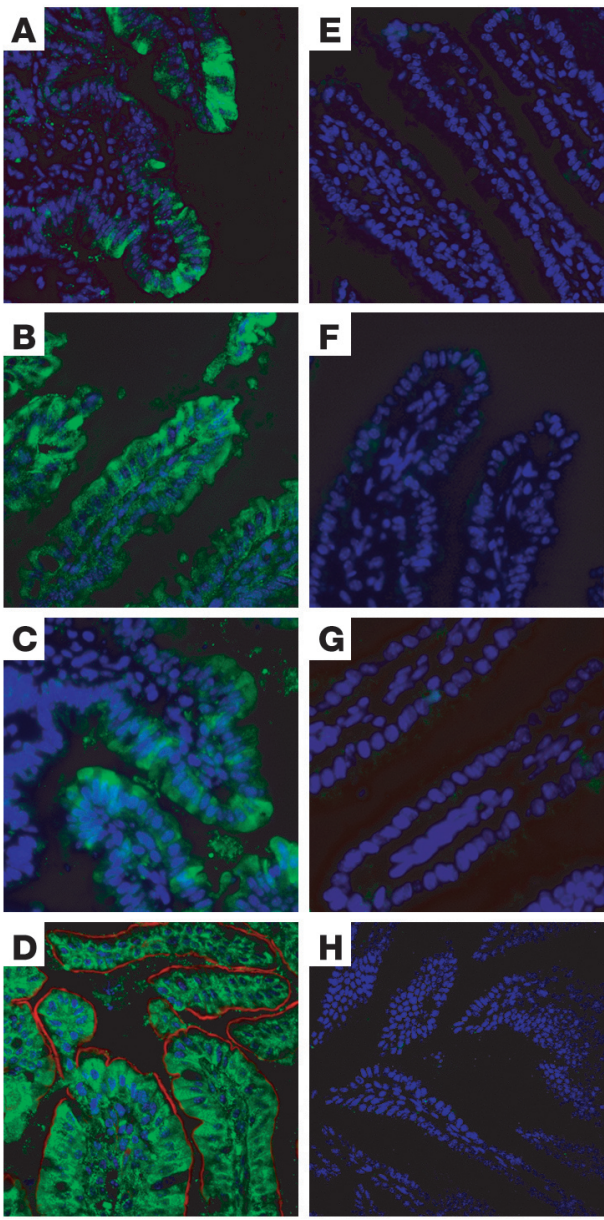

Fast protein liquid chromatography (FPLC) analysis confirmed the significant decrease in HDL cholesterol concentration in Abca $1^{-i /-i}$ mice (Figure 3A). No shift in particle size was evident, indicating that the reduction in HDL cholesterol primarily reflected a reduction in the number of similarly sized particles. Quantification of the cholesterol concentration in the FPLCseparated lipoprotein classes confirmed that HDL cholesterol was reduced by approximately $30 \%$ in $A b c a 1^{-i /-i}$ homozygotes $(P<0.05$; Figure $3 \mathrm{~B})$ and also revealed a significant decrease in LDL cholesterol concentration $(P<0.05$; Figure $3 \mathrm{~B})$, similar to that observed in Tangier disease patients and in ABCA1 total knockout mice $(40,41)$.

To determine the cumulative contribution of intestinal and hepatic ABCA1 to plasma HDL cholesterol levels, we bred mice that carry both the Villin-Cre and the Albumin-Cre trans-

\section{Figure 2}

Expression of ABCA1 in mouse intestine. Ten-micron sections of mouse intestine were stained with an antibody against ABCA1 (green), or with DAPI (blue) or phalloidin (red). (A-C) lleum, $\times 20$ magnification (A) and $\times 40$ magnification (B and C), from Abca1+/+ mice. (E-G) Corresponding sections from $A b c a 1^{-i /-i}$ mice. (D) Jejunum, $\times 60$ magnification, from $A b c a 1^{+/+}$mouse. $(\mathbf{H})$ Jejunum, $\times 60$ magnification, from $A b c a 1^{+/+}$mouse stained with random mouse IgG as negative control.

genes, such that ABCA1 is deleted from both liver and intestine $\left(A b c a 1^{-i L /-i L}\right)$. Figure 4A shows plasma HDL cholesterol levels in control mice, and mice lacking intestinal ABCA1, hepatic ABCA1, or both. Compared with mice lacking hepatic ABCA1, mice lacking both intestinal and hepatic ABCA1 displayed a further significant decrease in plasma HDL cholesterol levels, indicating that the contribution of intestinal ABCA1 to HDL cholesterol levels was independent of hepatic ABCA1. Figure 4B shows HDL cholesterol levels as a percentage of respective ageand strain-matched controls. The combined deletion of both hepatic and intestinal ABCA1 resulted in an approximately $90 \%$ decrease in plasma HDL cholesterol levels, similar to that seen in ABCA1 total knockout mice. Therefore, the intestine and liver are the 2 major sites of initial HDL particle assembly, and $\mathrm{ABCA} 1$ in other tissues cannot compensate for the loss of hepatic and intestinal ABCA1.

To study the metabolic effects of loss of intestinal ABCA1 on intestinal cholesterol transport, we fed $\mathrm{Abca}^{+/+}$and $\mathrm{Abca1^{-i/-i }}$ mice $\left[{ }^{3} \mathrm{H}\right]$ cholesterol and measured the appearance of the cholesterol tracer in plasma, liver, and intestine after 2 hours. Figure 5A shows the appearance of $\left[{ }^{3} \mathrm{H}\right]$ cholesterol in plasma, HDL, and non-HDL 2 hours after oral gavage. Mice lacking intestinal ABCA1 had a significant approximately $35 \%$ reduction in the level of $\left[{ }^{3} \mathrm{H}\right]$ cholesterol in plasma and HDL after 2 hours $(P<0.05)$. $\left[{ }^{3} \mathrm{H}\right]$ cholesterol appearance in non-HDL was not significantly different between genotypes. Figure 5, B and C, shows the amount of $\left[{ }^{3} \mathrm{H}\right]$ cholesterol recovered in the liver and in the intestine after a luminal rinse, at 2 hours after the oral gavage. $A b c a 1^{-i /-i}$ mice displayed significantly less $\left[{ }^{3} \mathrm{H}\right]$ cholesterol in the liver $(P<0.05$; Figure 5B) as well as significant retention of $\left[{ }^{3} \mathrm{H}\right]$ cholesterol in the small intestine compared with controls ( $P<0.05$; Figure $5 \mathrm{C})$. These data indicate that cholesterol uptake from the intestinal lumen is not impaired in mice lacking intestinal ABCA1, but that the transport of absorbed cholesterol into plasma is significantly reduced. The reduced appearance of radiolabeled cholesterol in plasma is unlikely to be secondary to the reduced plasma HDL cholesterol pool in these mice, because it has previously been shown that raising plasma HDL levels does not prevent decreased appearance of a gavaged cholesterol tracer in plasma in a chicken model of total ABCA1 deficiency (42).

Table 1

Plasma lipid and apolipoprotein values for ABCA1 intestine-specific knockout mice consuming a standard laboratory chow diet

\begin{tabular}{|c|c|c|c|c|c|c|c|}
\hline Abca1 genotype & TPC (mg/dl) & HDL-C (mg/dl) & TG (mg/dl) & ApoA-I (mg/dl) & ApoA-II (mg/dl) & ApoCIII (mg/dl) & ApoB (mg/dl) \\
\hline $\begin{array}{l}+/+ \\
+/-i \\
-i /-i\end{array}$ & $\begin{array}{r}116 \pm 5(21) \\
96 \pm 6(13)^{\mathrm{A}} \\
81 \pm 7(14)^{\mathrm{B}}\end{array}$ & $\begin{array}{l}75 \pm 2(31) \\
63 \pm 5(12)^{A} \\
49 \pm 6(10)^{B}\end{array}$ & $\begin{aligned} 105 & \pm 12(9) \\
91 & \pm 9(8) \\
105 & \pm 10(6)\end{aligned}$ & $\begin{array}{l}81 \pm 4(9) \\
76 \pm 6(8) \\
61 \pm 10(6)^{A}\end{array}$ & $\begin{array}{l}152 \pm 9(9) \\
128 \pm 15(8) \\
101 \pm 17(6)^{A}\end{array}$ & $\begin{array}{l}58 \pm 7(9) \\
51 \pm 7(8) \\
43 \pm 4(6)\end{array}$ & $\begin{array}{l}21 \pm 1(9) \\
18 \pm 2(8) \\
15 \pm 1(6)^{\mathrm{A}}\end{array}$ \\
\hline
\end{tabular}


A
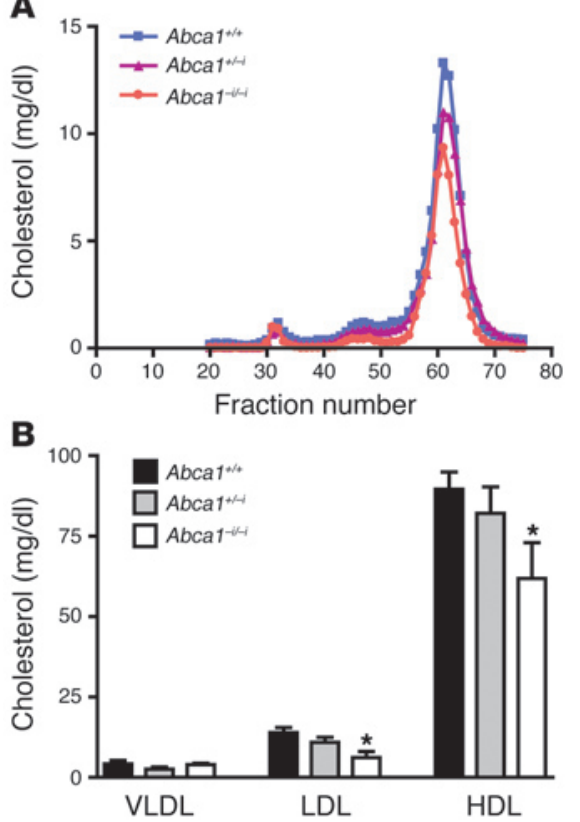

To further assess the role of enterocyte ABCA1 in the uptake of luminal cholesterol, we measured fractional cholesterol absorption by the fecal dual-isotope method. Figure 5D shows fractional cholesterol absorption in $A b c a 1^{+/+}$and $A b c a 1^{-i /-i}$ mice. We found no effect on this parameter in the absence of intestinal ABCA1, indicating that enterocyte ABCA1 does not influence luminal cholesterol absorption.

Figure 6 shows intestinal and hepatic cholesterol content in control mice and mice lacking intestinal ABCA1. Mice lacking intestinal ABCA1 displayed a trend toward increased total and free cholesterol in the small intestine, and a significant 10-fold increase in intestinal cholesterol ester content $(P<0.05$; Figure 6A). There was no difference in hepatic cholesterol content (Figure 6B). Figure 6C shows the relative amounts of mRNAs involved in sterol metabolism in intestines of control and $A b c a 1^{-i /-i}$ mice. Mice lacking intestinal ABCA1 had significantly increased levels of $A b c g 5$ and $A b c g 8$ $(P<0.05)$ as well as a trend toward reduced levels of HMG-CoA synthase $(H m g c s)$ mRNA $(P=0.06)$. These gene expression changes are consistent with increased sterol content in enterocytes, leading to activation of liver $\mathrm{X}$ receptor target genes such as ABCG5 and ABCG8 (43), and suppression of cholesterol synthesis genes. No change was observed in the levels of Npc1l1 mRNA, the putative cholesterol absorption protein $(44,45)$, consistent with our finding of normal cholesterol absorption in $A b c a 1^{-i /-i}$ mice (Figure 5D).

\section{Figure 4}

Tissue-specific contributions of ABCA1 to plasma HDL cholesterol levels. (A) Plasma HDL cholesterol levels in control mice, and mice lacking intestinal $A B C A 1(-i /-i)$, hepatic ABCA1 (-L/-L), or both (-iL/-iL). Mice lacking both hepatic and intestinal $A B C A 1$ had a further significant decrease in plasma HDL cholesterol compared with mice lacking hepatic ABCA1. (B) Plasma HDL cholesterol levels as a percentage of those of strain-matched controls. The percentage decrease compared with strain-matched controls is indicated over each bar. Deletion of hepatic and intestinal ABCA1 results in an approximately $90 \%$ decrease in plasma HDL cholesterol, similar to that in mice lacking ABCA1 globally $(-/-) . n \geq 4$ mice per group. ${ }^{*} P<0.01$.

\section{Figure 3}

Analysis of plasma lipoproteins by FPLC. (A) Equal volumes of plasma from $A b c a 1^{+/+}, A b c a 1^{+/-i}$, and $A b c a 1^{-i /-i}$ mice fasted for 4 hours were pooled and fractionated by FPLC. Total cholesterol in each fraction was determined by enzymatic assay. (B) Plasma from individual mice fasted for 4 hours was fractionated, and cholesterol concentration was determined online by FPLC. $n=6-9$ mice per group. ${ }^{\star} P<0.05$.

To further characterize the mechanism by which intestinal ABCA1 influences plasma HDL cholesterol levels and intestinal lipid transport, we investigated cholesterol secretion by primary enterocytes isolated from $A b c a 1^{+/+}$and $A b c a 1^{-i /-i}$ mice. This system has previously been shown to accurately model the secretion of cholesterol into both apoB-containing chylomicron and VLDL-sized particles, as well as non-apoB-containing particles in the size range of $\operatorname{HDL}(29,30)$. Primary enterocytes were isolated and incubated with $\left[{ }^{3} \mathrm{H}\right]$ cholesterol and then chased for 2 hours in the presence of micelles. Figure 7, A and B, shows $\left[{ }^{3} \mathrm{H}\right]$ cholesterol levels in cells and media, respectively, after 2 hours. Enterocytes from $A b c a 1^{-i /-i}$ mice contained significantly more $\left[{ }^{3} \mathrm{H}\right]$ cholesterol (Figure $7 \mathrm{~A}$ ) and secreted less $\left[{ }^{3} \mathrm{H}\right]$ cholesterol into the media over 2 hours (Figure 7B).

The media were subsequently subjected to density gradient ultracentrifugation, and $\left[{ }^{3} \mathrm{H}\right]$ cholesterol was determined in the isolated fractions. Figure $7 \mathrm{C}$ shows $\left[{ }^{3} \mathrm{H}\right]$ cholesterol levels in the isolated fractions. Enterocytes lacking ABCA1 secreted $40 \%$ less $\left[{ }^{3} \mathrm{H}\right]$ cholesterol specifically into the highest-density fractions in the density range of HDL, which contain most of the secreted apoA-I $(29,30)(P<0.001$; Figure $7 \mathrm{C})$. In contrast, there was no difference in cholesterol secretion into the lower-density fractions representing chylomicrons and VLDL (fractions 1-3), which contain most of the apoB $(29,30)$. These in vitro results therefore recapitulate the findings in vivo that absence of enterocyte ABCA1 results in accumulation of cellular cholesterol, and reduced secretion of cholesterol. These data further indicate that ABCA1 is directly involved in the secretion of cellular cholesterol into HDL from enterocytes.

Cholesterol secretion by the intestine is thought to occur almost exclusively via the lymphatics (23). As Abca1 $1^{-i /-i}$ mice had
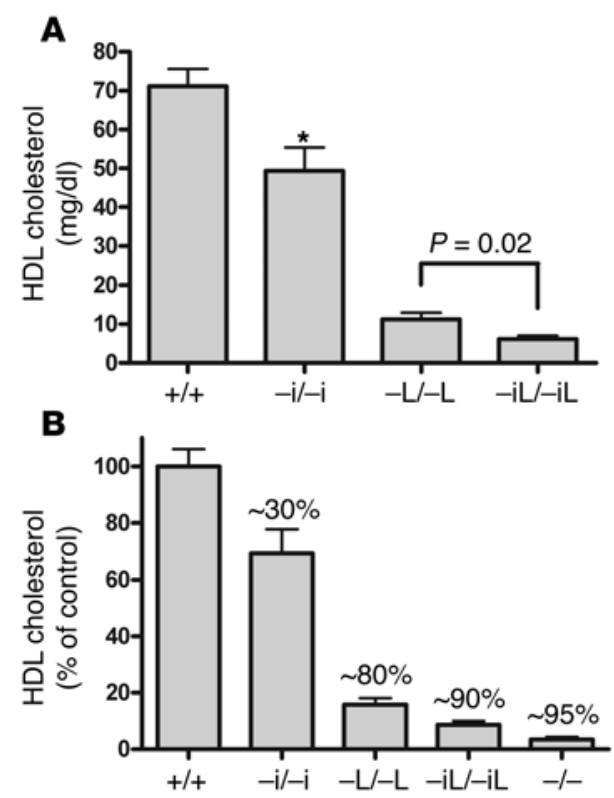
A

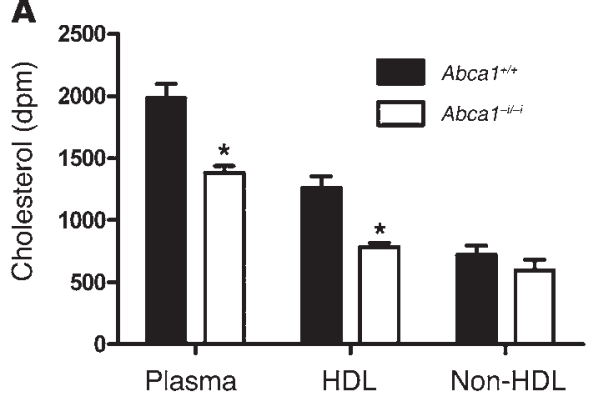

C

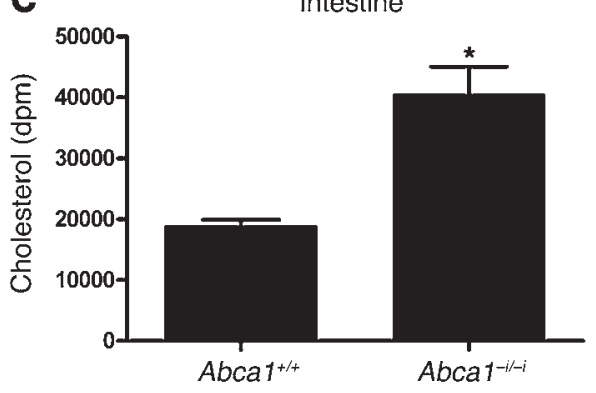

B

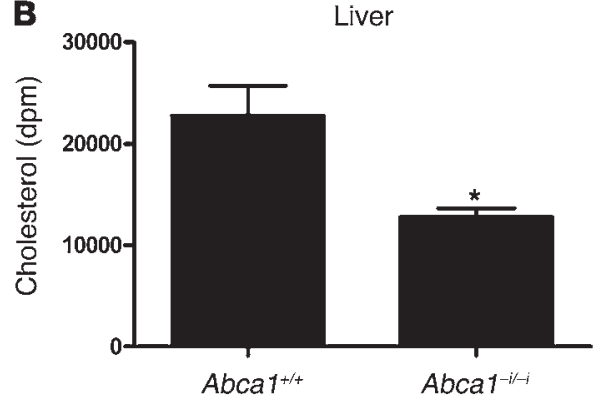

D

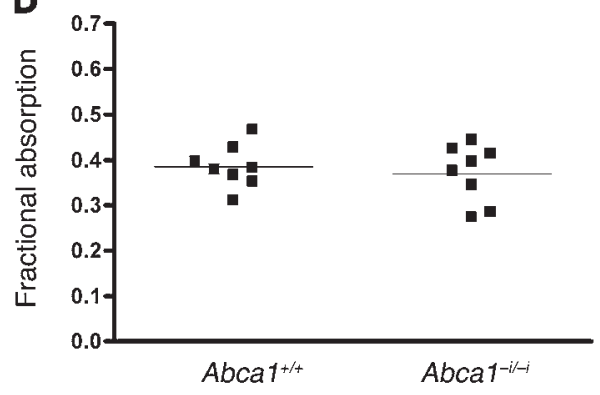

\section{Figure 5}

Intestinal cholesterol transport in mice lacking intestinal ABCA1. (A) Appearance of $\left[{ }^{3} \mathrm{H}\right]$ cholesterol in whole-plasma, $\mathrm{HDL}$, and non-HDL fractions after 2 hours. Mice were gavaged with $0.2 \mu \mathrm{Ci}$ of $\left[{ }^{3} \mathrm{H}\right]$ cholesterol, and the appearance of the tracer was assessed after 2 hours. (B) $\left[{ }^{3} \mathrm{H}\right]$ cholesterol in liver 2 hours after oral gavage. (C) $\left[{ }^{3} \mathrm{H}\right]$ cholesterol in small intestine 2 hours after oral gavage. The small intestine was rinsed with PBS to remove luminal contents. (D) Fractional cholesterol absorption determined by fecal dual-isotope method. $n=6$ mice per group. ${ }^{*} P<0.05$. impaired transport of dietary cholesterol into plasma, we examined whether this was due to decreased transport of cholesterol via lymph. The mesenteric lymph ducts of $A b c a 1^{+/+}$and $A b c a 1^{-i /-i}$ mice were cannulated, and lymph was collected during an intraduodenal infusion of $4 \%$ Intralipid containing $\left[{ }^{14} \mathrm{C}\right]$ cholesterol and $\left[{ }^{3} \mathrm{H}\right]$ oleate. Lymph production rates were similar in both groups of mice (approximately $0.10-0.15 \mathrm{ml} / \mathrm{h}$ ). Figure 8 , A and B, shows the rate of transport of cholesterol and triglyceride into mesenteric lymph in $A b c a 1^{+/+}$and $A b c a 1^{-i /-i}$ mice. There were no significant differences in lipid transport rate between genotypes, indicating that total lymphatic lipid transport is not altered by the absence of intestinal ABCA1. Monitoring the appearance of $\left[{ }^{14} \mathrm{C}\right]$ cholesterol and $\left[{ }^{3} \mathrm{H}\right]$ oleate in lymph (Figure $8 \mathrm{C}$ ) revealed that the rate of appearance of $\left[{ }^{14} \mathrm{C}\right] \mathrm{cholesterol}$ in lymph as a fraction of $\left[{ }^{3} \mathrm{H}\right]$ oleate was not significantly different in $\mathrm{Abca1^{+/+ }}$ compared with $A b c a 1^{-i /-i}$ mice $(0.53 \pm 0.2$ versus $0.65 \pm 0.2$ after 4 hours, $P=0.7)$, indicating that intestinal ABCA1 does not participate in the transport of dietary cholesterol into lymph.

Lymph collected from mice of each genotype was pooled and subjected to FPLC separation. Lymph from $\mathrm{Abca1^{+/+ }}$ mice showed a major cholesterol peak corresponding to chylomicron/ VLDL-sized particles and a minor peak in the size range of HDL, confirming that HDL cholesterol was present in the mesenteric lymph of WT mice (Figure 8D). Surprisingly, lymph from $A b c a 1^{-i /-i}$ mice showed a similar cholesterol profile to that of WT mice. A slight reduction was evident in the amounts of cholesterol in chylomicron/VLDL-sized fractions. However, measurement of cholesterol in chylomicrons isolated by density gradient ultracentrifugation revealed that this difference was not statistically significant $(0.70 \pm 0.07$ versus $0.59 \pm 0.06 \mathrm{mM}, P=0.3)$. Notably, $A b c a 1^{-i /-i}$ and $A b c a 1^{+/+}$mice had equivalent amounts of cholesterol in HDL-sized fractions (Figure 8D). This finding indicates that lymph HDL arises independently of intestinal ABCA1. Assessing the distribution of $\left[{ }^{14} \mathrm{C}\right]$ cholesterol across the FPLCseparated lipoprotein fractions showed that virtually all of the radiolabeled cholesterol secreted into lymph was associated with the chylomicron/VLDL-sized fractions in both and $\mathrm{Abca1^{+/+ }}$ and Abca $1^{-i /-i}$ mice, with essentially no $\left[{ }^{14} \mathrm{C}\right]$ cholesterol detectable in HDL-sized fractions (Figure 8E).

We reasoned that HDL cholesterol present in mesenteric lymph could either arise from the intestine in an ABCA1-independent manner, or be derived from the plasma, as some reports have suggested (32-36). To determine whether lymph HDL originates from plasma, we collected mesenteric lymph from mice in which ABCA 1 is deleted in the liver but is present in extrahepatic tissues, including the intestine (Abca1 $1^{-L / L}$ mice) (16). Abca $1^{-L /-L}$ mice have an approximately $80 \%$ reduction in plasma HDL cholesterol levels, and any alteration in lymph lipoprotein concentration detected in $A b c a 1^{-L / L}$ mice should be directly attributable to the action of hepatic ABCA1. Lymph from $A b c a 1^{-L /-L}$ mice had no detectable HDL cholesterol (Figure 8F), whereas the distribution of $\left[{ }^{14} \mathrm{C}\right]$ cholesterol among FPLC fractions was unchanged (Figure 8G). In addition, the HDL-sized fractions from $A b c a 1^{-L / L}$ lymph contained only trace amounts of apoA-I in comparison to the equivalent fractions in lymph from WT and $A b c a 1^{-i /-i}$ mice (Figure $8 \mathrm{H}$ ). These data indicate that HDL present in mesenteric lymph of mice is not secreted by the intestine and suggest that it originates from the plasma compartment.

\section{Discussion}

Using a novel mouse model in which ABCA1 is specifically inactivated in the intestine, we have shown that intestinal ABCA1 is critically involved in HDL biogenesis, contributing approximately $30 \%$ to the steady-state plasma HDL cholesterol pool. Intestinal $\mathrm{ABCA} 1$ acts by directly mediating cholesterol transfer toward plasma HDL, and absence of intestinal ABCA1 is associated with decreased transport of intraluminally administered cholesterol into plasma. The absence of intestinal ABCA1 was shown to have no effect on the transfer of luminal cholesterol into lymph and on lymphatic HDL particle content, suggesting that secretion of HDL by the intestine occurs into plasma. Finally, analysis of lymph from liver-specific ABCA1-deficient 
A

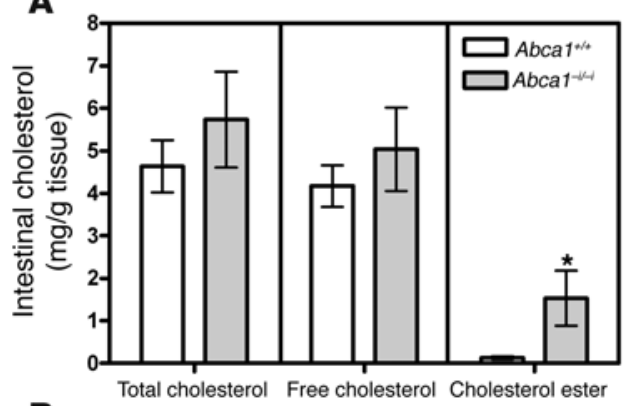

B

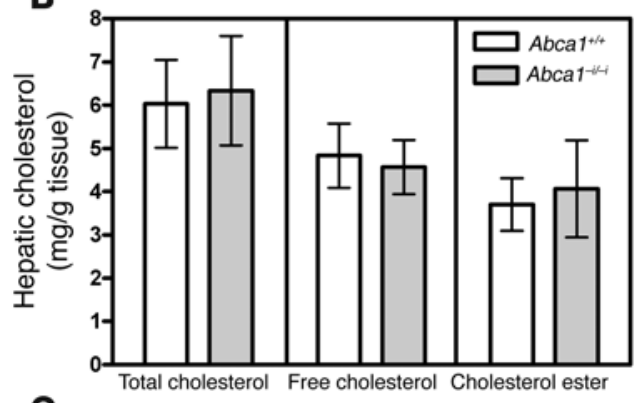

C

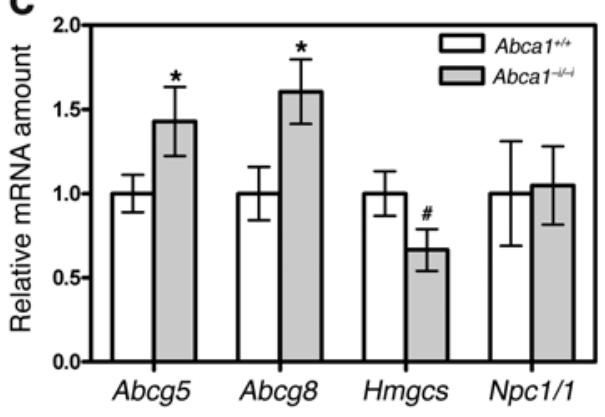

mice with very low plasma HDL levels provides evidence that HDL present in mouse lymph originates from plasma.

Since the discovery of the highly significant inverse relationship between HDL cholesterol concentration and risk for coronary heart disease (46), the origin of plasma HDL has been a subject of intense study. Successful development of therapeutic strategies to raise HDL levels relies crucially on knowledge of the molecular

\section{Figure 6}

Tissue cholesterol levels and gene expression. (A) Intestinal cholesterol levels in control mice and mice lacking intestinal ABCA1. $n=3$ mice per group. (B) Hepatic cholesterol levels in control mice and mice lacking intestinal ABCA1. $n=3$ mice per group. (C) Relative amounts of various mRNAs in intestines from control mice and mice lacking intestinal $A B C A 1$. Values are relative to the mRNA amount in control mice, which is arbitrarily set as $1 . n=4-8$ mice per group. ${ }^{*} P<0.05$. ${ }^{\#} P=0.06$.

nature of HDL particle formation as well as the cellular origin of these particles. However, it has not been until recently that we have had the tools necessary to address these questions.

The original conceptualization of the reverse cholesterol transport theory, as described by Glomset $(1,2)$, postulated that HDL cholesterol would be mainly of peripheral origin and would be transported to the liver for removal from the body by excretion into bile. The discovery of ABCA1 as the cause of Tangier disease (6-8), and the finding that the ABCA1 gene product is indispensable for the maintenance of plasma HDL cholesterol levels in mice $(39,41,47)$, have shed new light on the molecular mechanisms of HDL biogenesis. ABCA1 is expressed widely throughout the body $(12,13)$, but only the liver and the intestine are known to synthesize apoA-I $(18,48)$. However, coexpression in the same tissue does not constitute evidence for a functional relationship. Overexpression of ABCA1 in the liver of mice via adenoviral delivery $(14,15)$ or by transgenesis under the control of either its endogenous (49) or an Apoe (50) promoter raises HDL levels and protects against atherosclerosis in mice with the Apoe ${ }^{-/-}$background (51). We have recently described mice with liver-specific deletion of hepatic ABCA1 (16), demonstrating the essential role of hepatic ABCA1 in both the biogenesis and the maintenance of plasma HDL. Here we report that deletion of intestinal ABCA1 results in a significant reduction in plasma HDL cholesterol in mice, establishing the intestine as a second crucial player in HDL biogenesis.

Absence of intestinal ABCA1 was shown to result in decreased transport of dietary cholesterol into HDL in vivo and in vitro, along with accumulation of cellular cholesterol. However, our data indicate that, in chow-fed mice, absence of intestinal ABCA1 does not affect fractional cholesterol absorption as determined by the fecal dual-isotope method. Previous stud-
A

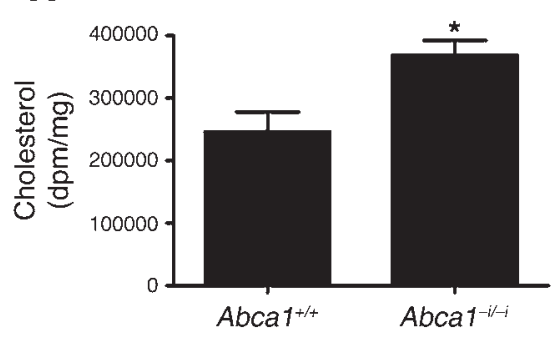

B

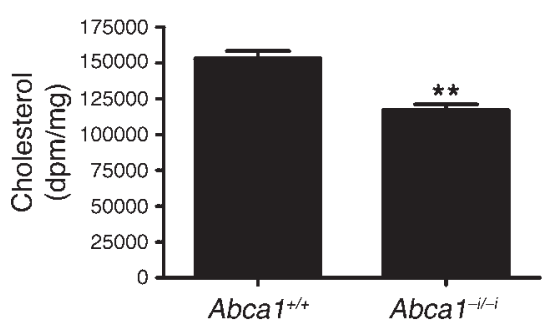

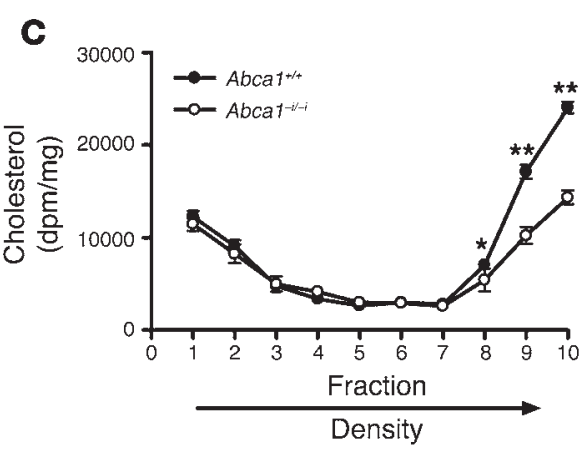

Figure 7

Cholesterol secretion from primary enterocytes. Primary enterocytes from $A b c a 1^{+/+}$and $A b c a 1^{-i /-i}$ mice were isolated and radiolabeled with $\left[{ }^{3} \mathrm{H}\right]$ cholesterol, then chased in the presence of micelles. $(\mathbf{A})\left[{ }^{3} \mathrm{H}\right]$ cholesterol remaining in cells after 2 hours of chase. $(B)\left[{ }^{3} \mathrm{H}\right]$ cholesterol in media after 2 hours chase. (C) Media were fractionated by ultracentrifugation, and $\left[{ }^{3} \mathrm{H}\right]$ cholesterol was measured in each fraction. $n=6$ per group. ${ }^{*} P<0.05$. ${ }^{* *} P<0.001$. 

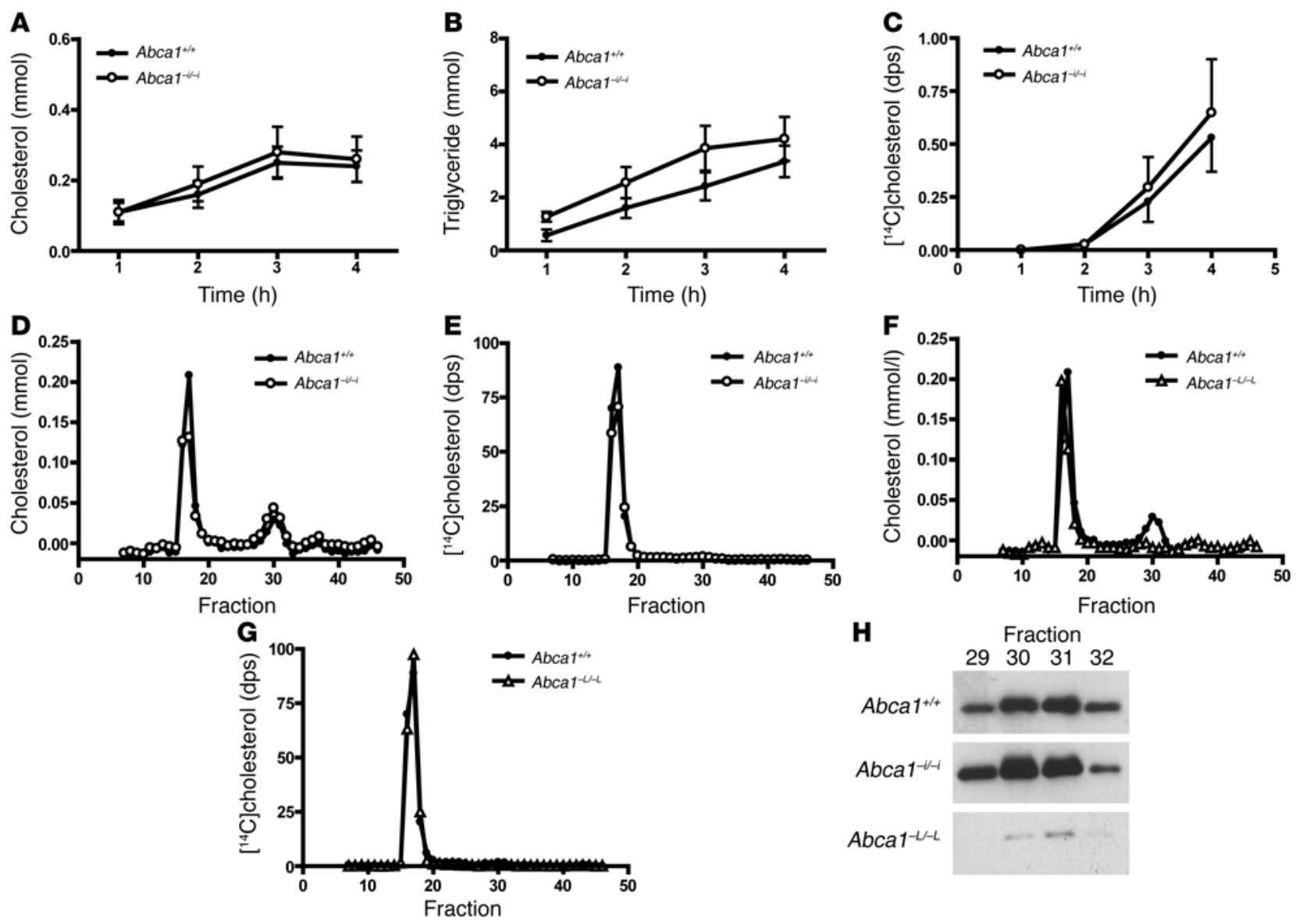

Figure 8

Analysis of lymph lipoproteins in $A b c a 1^{+/+}$and $A b c a 1^{-i /-i}$ mice. (A) Lymph cholesterol transport rate in $A b c a 1^{+/+}$and $A b c a 1^{-i /-i}$ mice. (B) Lymph triglyceride transport rate in $A b c a 1^{+/+}$and $A b c a 1^{-i /-i}$ mice. (C) Appearance of $\left[{ }^{14} \mathrm{C}\right]$ cholesterol in lymph during intraduodenal infusion as a fraction of [ $\left.{ }^{3} \mathrm{H}\right]$ oleate. (D) FPLC analysis of lymph from $A b c a 1^{+/+}$and $A b c a 1^{-i /-i}$ mice. (E) Distribution of $\left[{ }^{14} \mathrm{C}\right]$ cholesterol in FPLC fractions of $A b c a 1^{+/+}$and

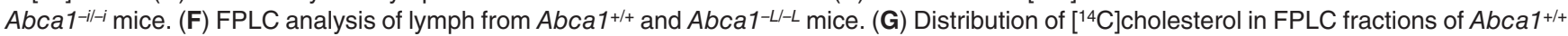
and $A b c a 1^{-L / L}$ mice. (H) Western blot of apoA-I in HDL-sized fractions from lymph of $A b c a 1^{+/+}, A b c a 1^{-i /-i}$, and $A b c a 1^{-L / L L}$ mice. $n \geq 6$ mice per group. dps, disintegrations per second.

ies assessing intestinal cholesterol absorption in mice lacking ABCA1 globally have yielded conflicting results $(41,52,53)$, suggesting that the overall effect of ABCA1 on absorption is at most minor (54). Our findings indicate that the primary function of enterocyte ABCA1 is to mediate the basolateral efflux of cholesterol and, presumably, phospholipids into plasma, a model that is supported by studies in CaCo- 2 cells $(29,55$, 56) and chickens lacking ABCA1 globally (42). Structural and functional polarity is a fundamental feature of enterocytes, and indeed of a variety of epithelial cell types involved in vectorial transport (57). It is therefore perhaps not surprising that while absence of intestinal ABCA1 impairs the basolateral transport of cellular cholesterol into plasma (Figure 5A), fractional cholesterol absorption as measured by fecal dual isotope, which assesses only luminal uptake, is not affected (Figure 5D). These results also indicate that the reduction in HDL cholesterol in plasma of $A b c a 1^{-i /-i}$ mice is the direct consequence of a secretory defect in enterocytes.

Results obtained in ABCA1-deficient enterocytes were similar to those observed in primary enterocytes lacking apoA-I (30), indicat- ing that $\mathrm{ABCA} 1$ and apoA-I are obligate partners for the secretion of HDL cholesterol from the intestine. While these data suggest that the intestine, along with the liver (16), is essential for the biogenesis of HDL particles, likely by initial lipidation of newly secreted apoA-I, it remains to be determined whether the bulk of cholesterol carried by these lipoproteins originates from the intestine and the liver, or, as implicated by the reverse cholesterol transport hypothesis, from peripheral tissues.

Cholesterol that is absorbed or synthesized locally in the intestine is thought to be secreted almost exclusively via the lymphatics, mostly in the form of cholesterol ester in chylomicrons and VLDL (23). Studies of the HDL of mesenteric lymph of rats also suggested that a portion of cellular cholesterol is secreted as HDL into lymph (25-27). Rat mesenteric lymph contains both discoidal and spherical HDL particles that are enriched in phospholipids and protein compared with plasma $\operatorname{HDL}(25,26)$, suggesting a distinct origin of these particles. We therefore hypothesized that $A b c a 1^{-i /-i}$ mice would have reduced HDL cholesterol in lymph, underlying the reduction in HDL cholesterol in plasma. 
Surprisingly, our lymph cannulation experiments showed that lymph HDL cholesterol and apoA-I contents were essentially unaffected in $A b c a 1^{-i /-i}$ mice, and furthermore that transport of luminal cholesterol into lymph is independent of enterocyte ABCA1. The fact that lymph HDL did not appear to decrease in $A b c a 1^{-i /-i}$ mice in proportion to their reduction in plasma HDL cholesterol may simply reflect an inability to detect small differences in the very small amounts of HDL present in mouse lymph. In addition, plasma lipid values were determined in fasted mice, whereas lymphatic analysis was performed on nonfasted, anesthetized mice, and it cannot be excluded that transudation of HDL from plasma into lymph, or lipolysis of lymph chylomicrons and VLDL, may be altered under these conditions. Importantly, the finding that absence of intestinal ABCA1 impairs the transport of luminal cholesterol into plasma (Figure 5A), but not into lymph (Figure 8C), suggests the existence of an alternative lipid transport system in enterocytes, by which ABCA1-mediated cholesterol efflux to form HDL occurs selectively into capillaries, while chylomicrons are secreted predominantly into lymphatics. The intestinal epithelium is in close contact with both capillaries and lymphatic vessels of the lamina propria, and indeed other nutrients, such as medium-chain fatty acids, are transported directly into the portal circulation (23). To our knowledge, intestinal transport of cholesterol into the circulation in mammals has not been previously demonstrated.

In contrast to $A b c a 1^{-i /-i}$ mice, lymph HDL cholesterol and apoA-I were virtually absent in $A b c a 1^{-L / L}$ mice, suggesting that the HDL present in the lymph of WT mice is dependent on the activity of hepatic ABCA1 and enters the lymph via the plasma. Consistent with this, orally administered $\left[{ }^{14} \mathrm{C}\right]$-labeled cholesterol was recovered only in chylomicron/VLDL-sized fractions in $A b c a 1^{+/+}$, $A b c a 1^{-i /-i}$, and $A b c a 1^{-L /-L}$ mice, indicating that in the time course of our experiments the intestine did not secrete cholesterol into lymph HDL. The origin of HDL particles in mesenteric lymph has been a subject of considerable controversy. Bearnot et al. demonstrated that, following i.v. injection of [ $\left.{ }^{125} \mathrm{I}\right]$ apoA-I-labeled HDL, the specific activity of lymph HDL-associated apoA-I did not exceed approximately $30 \%$ of that of plasma HDL-associated apoA-I, suggesting intestinal secretion of HDL apoA-I into lymph (28). In addition, Forester et al. reported that after duodenal infusion of $\left[{ }^{3} \mathrm{H}\right]$ cholesterol the specific activity of lymph HDL was much higher than that of plasma HDL, although the same study also reported significant transfer of free cholesterol between different lipoprotein classes (26). Other studies have suggested that transudation from plasma represents the major origin of lymph HDL (32-36). Because of the rapid exchange of apoproteins and lipid constituents among lipoprotein classes $(58,59)$, radiolabeling experiments may not be able to correctly determine the origin of the radiolabeled particles. The reasons for the discrepancies between our results and those suggesting secretion of intestinal HDL into lymph $(25,26,28,60)$ remain unclear. In most of the studies performed in rats, lymph was collected in the presence of an inhibitor of lecithin cholesterol acyltransferase, which we did not use, and some of these discrepancies may also be due to species differences between mice and rats. In addition, the small amounts of apoA-I in lymph HDL fractions of $A b c a 1^{-L /-L}$ mice may represent intestinally derived HDL that arises independently of ABCA1. Our data showing near absence of lymph HDL cholesterol and apoA-I in $A b c a 1^{-L /-L}$ mice are most consistent with a model in which lymph $\mathrm{HDL}$ is predominantly derived from the plasma.
Patients with Tangier disease have long been recognized to have reduced LDL cholesterol and altered LDL composition, in addition to nearly absent HDL cholesterol (61). The mechanisms by which ABCA1 impacts the metabolism of apoB-containing lipoproteins are unclear (62). One mechanism involves an inability of HDL to supply cholesterol esters to LDL via cholesterol ester transfer protein (CETP) (63). However, this is unlikely to be the sole mechanism, since patients with apoA-I deficiency also lack plasma HDL cholesterol but do not exhibit the reduction in LDL cholesterol observed in Tangier disease (64), and mice that lack ABCA1 globally or in the liver have reduced LDL cholesterol but do not have CETP $(16,41)$. Abca $1^{-i /-i}$ mice have significantly reduced $\mathrm{LDL}$ cholesterol and $\mathrm{apoB}$ despite their more modest decrease in HDL cholesterol, suggesting that the reduced HDL cholesterol may not entirely underlie the reduction in plasma LDL cholesterol. In addition, lymph chylomicron/VLDL cholesterol was slightly decreased in $A b c a 1^{-i /-i}$ mice, though this difference was not significant when lymph chylomicron levels were compared after isolation by density gradient ultracentrifugation. Our studies in primary enterocytes from $A b c a 1^{-i /-i}$ mice suggest that secretion of cholesterol into apoB-containing particles is not impaired (Figure 7C), as it similarly is not impaired in enterocytes isolated from mice lacking apoA-I (30); this contrasts with enterocytes in which microsomal transfer protein is inhibited (29). These results suggest that intestinal ABCA1 and hepatic ABCA1 may have direct effects on plasma LDL cholesterol that are not entirely dependent on their effects on HDL cholesterol concentration.

In summary, our results establish that the intestine is crucially involved in the maintenance of plasma HDL levels through the actions of ABCA1 and, in addition, suggest that intestinally derived HDL may enter the circulation directly rather than via the lymph. Additional studies are necessary to determine whether deletion of intestinal ABCA1 confers increased risk of atherosclerosis and thus whether the intestine plays an atheroprotective role as a component of its normal physiological function.

\section{Methods}

Animals. Abca1 floxed mice were generated by insertion of loxP sites into introns 44 and 46 of the murine $A b c a 1$ gene in a $129 \mathrm{~Sv} / \mathrm{Ev}$ embryonic stem cell that was injected into a C57BL/6 blastocyst, as previously described (16). Mice with intestine-specific deletion of ABCA1 were generated by crossing of Abca1 floxed mice with Villin-Cre transgenic mice, generously provided by Deborah Gumucio (University of Michigan, Ann Arbor, Michigan, USA) (37), to generate $A b c a 1^{+/-i}$ heterozygotes. Intercrossing led to the $A b c a 1^{+/+}, A b c a 1^{+/-i}$, and $A b c a 1^{-i /-i}$ mice used in this study. Control mice, collectively designated $A b c a 1^{+/+}$, consisted of littermates carrying floxed Abca1 alleles in the absence of Cre, or WT Abca1 alleles in the presence or absence of Cre, and plasma HDL cholesterol levels between these 2 groups were not different (see Supplemental Figure 1; supplemental material available online with this article; doi:10.1172/JCI27352DS1). ABCA1 liverspecific knockout mice (Abca1 $1^{-L / L}$ ) have been previously described (16). Mice lacking hepatic and intestinal ABCA1 were generated by breeding of $A b c a 1^{-L /-L}$ and $A b c a 1^{-i /-i}$ mice, and genotypes with regard to Villin-Cre or Albumin-Cre transgenes were determined by promoter-specific PCR. ABCA1 global knockout mice (Abca1-/-) were generously provided by Omar Francone (Pfizer Global Research and Development, Groton, Connecticut, USA) (41). Animals were housed under 12-hour light/dark cycles and received a standard laboratory chow diet. These studies were approved by the University of British Columbia Animal Care Committee. 
Southern analysis. Southern blotting was performed as previously described (16). Briefly, genomic DNA was isolated from indicated tissues, digested with proteinase $\mathrm{K}$, and incubated with EcoRV restriction enzyme (Promega). Digested DNA was separated on a $0.8 \%$ agarose gel and transferred to Nytran SuPerCharge nylon membrane (Schleicher \& Schuell BioScience Inc.). Southern blots were hybridized with a probe spanning intron 44 to yield the $6-\mathrm{kb}, 7.3-\mathrm{kb}$, and $4.2-\mathrm{kb}$ fragments corresponding to the WT, floxed, and knockout alleles, respectively.

Western analysis and real-time PCR. Western blotting was performed as previously described (12). Briefly, tissues were homogenized and sonicated in $20 \mathrm{mM}$ HEPES, $5 \mathrm{mM} \mathrm{KCl}, 5 \mathrm{mM} \mathrm{MgCl} 2,0.5 \%$ (vol/vol) Triton X-100, and complete protease inhibitor (Roche Diagnostics Corp.), and protein concentration was determined by the Lowry assay. Equivalent amounts of total protein were separated by SDS-PAGE, transferred to PVDF membranes, and probed with anti-ABCA1 (12) or anti-GAPDH (Chemicon International) antibodies. For lymph samples, equal volumes of FPLC fractions were separated by SDS-PAGE and probed with an anti-apoA-I antibody (Chemicon International).

RNA was isolated using TRIzol reagent according to manufacturer's instructions (Invitrogen Corp.). Three micrograms of RNA was reversetranscribed with SuperScript II (Invitrogen Corp.) to generate cDNA for real-time PCR using SYBR Green PCR Master Mix (Applied Biosystems) in an ABI PRISM 7700 Sequence Detection system. The following primer sequences were used: mAbcA1F CGTTTCCGGGAAGTGTCCTA, mAbcA1R CTAGAGATGACAAGGAGGATGGA, mGapdhF TGCACCACCAACTGCTTAG, mGapdhR GATGCAGGGATGATGTTC, mNpc111F TGGACTGGAAGGACCATTTCC, mNpc111R GCGCCCCGTAGTCAGCTAT, mAbcg5F TGGCCCTGCTCAGCATCT, mAbcg5R ATTTTTAAAGGAATGGGCATCTCTT, mAbcg8F CGTCGTCAGATTTCCAATGA, mAbcg8R GGCTTCCGACCCATGAATG, mHmgcsF GCCGTGAACTGGGTCGAA, and HmgcsR GCATATATAGCAATGTCTCCTGCAA.

Immunofluorescence. Mouse intestines were fixed in 3\% paraformaldehyde for 3 hours, and unfrozen $10-\mu \mathrm{m}$ sections were cut and mounted on slides. Samples were blocked in $10 \%$ normal goat serum for 30 minutes in $0.1 \% \mathrm{BSA} / 0.1 \%$ Tween-20/PBS, incubated with a polyclonal antibody directed against ABCA1 (12) at a concentration of $10 \mu \mathrm{g} / \mathrm{ml}$, followed by a goat anti-rabbit IgG secondary antibody, and then washed and counterstained with DAPI or phalloidin prior to coverslipping. Images were captured with a Zeiss Axioplan 2 camera and analyzed using MetaMorph software (Molecular Devices).

Plasma and tissue lipid analysis. Plasma lipid concentrations were determined in mice fasted for 4 hours as previously described (51). Briefly, cholesterol and triglyceride concentrations were determined by enzymatic assays using commercially available reagents (bioMérieux). Plasma HDL cholesterol levels were determined after precipitation of apoB-containing lipoproteins with phosphotungstic acid (Roche Diagnostics Corp.). Plasma levels of apoA-I, apoA-II, apoB, and apoC-III were measured by an immunonephelometric assay using specific mouse polyclonal antibodies as described previously (65). FPLC was preformed as previously described (65). This system allows separation of the 3 major lipoprotein classes - VLDL plus IDL; LDL; and HDL - in individual animals. Cholesterol concentrations were determined in the eluted fractions. Accumulated data were analyzed by the Millennium 2010 program (Waters Corp.).

Intestinal and hepatic free and total cholesterol was determined by gasliquid chromatography, as previously described (66).

Enterocyte studies. Mouse primary enterocyte studies were performed according to published protocols $(29,30)$. Briefly, freshly isolated enterocytes were incubated with $1 \mu \mathrm{Ci} / \mathrm{ml}$ of $\left[{ }^{3} \mathrm{H}\right]$ cholesterol in DMEM at $37^{\circ} \mathrm{C}$ with constant shaking, and cell suspensions were gassed with $95 \% \mathrm{O}_{2}, 5 \%$
$\mathrm{CO}_{2}$. After 1 hour, enterocytes were centrifuged at $15 \mathrm{~g}$ for 5 minutes, and the cell pellets were washed twice with DMEM (Invitrogen Corp.), and incubated at $37^{\circ} \mathrm{C}$ with micelles containing $0.14 \mathrm{mM}$ sodium cholate, $0.15 \mathrm{mM}$ sodium deoxycholate, $0.17 \mathrm{mM}$ phosphatidylcholine, $1.2 \mathrm{mM}$ oleic acid, and $0.19 \mathrm{mM}$ monopalmitoylglycerol. At the end of the incubation, enterocytes were centrifuged ( $15 \mathrm{~g}, 5$ minutes), and radioactivity in media was counted directly or in fractions following density gradient ultracentrifugation, performed as previously described (29). Total lipids were extracted from cells with isopropanol and counted by liquid scintillation, and proteins were dissolved in $0.1 \mathrm{~N} \mathrm{NaOH}$ and measured by the Bradford method (67). Data represent 6 mice per genotype.

Cholesterol absorption. Acute cholesterol absorption was determined as previously described (30). Briefly, mice fasted overnight were gavaged with $0.2 \mu \mathrm{Ci}\left[{ }^{3} \mathrm{H}\right]$ cholesterol (New England Nuclear) and $0.2 \mathrm{mg}$ unlabeled cholesterol in $15 \mu \mathrm{l}$ olive oil. After 2 hours, plasma, liver, and small intestine (first $20 \mathrm{~cm}$ from pylorus) were harvested, and $\left[{ }^{3} \mathrm{H}\right]$ content was determined by liquid scintillation counting. Data for liver represent $\mathrm{dpm}$ per tissue mass multiplied by total liver mass, and data for plasma represent dpm per milliliter plasma multiplied by total mouse plasma volume (estimated by mass of animal). Data represent 3-6 mice per genotype.

For fecal dual-isotope studies to quantify fractional cholesterol absorption, mice were gavaged with $0.1 \mu \mathrm{Ci}\left[{ }^{14} \mathrm{C}\right]$ cholesterol and $0.2 \mu \mathrm{Ci}$ $\left[{ }^{3} \mathrm{H}\right]$ sitosterol (American Radiolabeled Chemicals Inc.) in $0.2 \mathrm{ml}$ soybean oil (Sigma-Aldrich), and feces were collected for 72 hours. Lipids were extracted from feces and counted by liquid scintillation spectroscopy. Fractional cholesterol absorption was calculated by the formula (dose $\left[{ }^{14} \mathrm{C}\right]:\left[{ }^{3} \mathrm{H}\right]$ - fecal $\left.\left[{ }^{14} \mathrm{C}\right]:\left[{ }^{3} \mathrm{H}\right]\right) /$ dose $\left[{ }^{14} \mathrm{C}\right]:\left[{ }^{3} \mathrm{H}\right]$.

Mesenteric lymph collection. Mesenteric lymph cannulation was performed as previously described (68) with minor adjustments. Nonfasted mice were anesthetized by i.p. injection of fentanyl/fluanisone $(1 \mathrm{ml} / \mathrm{kg})$ and diazepam $(10 \mathrm{mg} / \mathrm{kg})$ and remained anesthetized over the course the experiment. After extra-abdominal displacement of the intestine, the main mesenteric lymph duct was punctured and cannulated with a $0.305 \times 0.635 \mathrm{~mm}$ (inner diameter $\times$ outer diameter) silicone tubing, which was primed with a heparin sodium solution $(1,000 \mathrm{U} / \mathrm{ml})$. A second cannula was inserted into the duodenum. Both cannulas were secured with tissue adhesive and externalized through the abdominal wall. After repositioning of the intestine, the abdominal incision was closed with 8-10 sutures. The animals received an infusion of $4 \%$ Intralipid $(0.3 \mathrm{ml} / \mathrm{h}$; Pharmacia) through the duodenal cannula during lymph collection. After 1 hour of lymph collection, animals received a lipid bolus via the duodenal cannula, containing $1 \mu \mathrm{Ci}$ of $\left[{ }^{14} \mathrm{C}\right]$ cholesterol and $0.1 \mu \mathrm{Ci}$ of $\left[{ }^{3} \mathrm{H}\right]$ oleate in $0.1 \mathrm{ml}$ of $4 \%$ Intralipid. Lymph was collected by gravity for 4 hours in total. Body temperature was stabilized using a humidified incubator. Cholesterol and triglyceride concentrations in lymph were determined as described for plasma. Pooled lymph samples of each group were used for lipoprotein separation by FPLC on a Superose 6B 10/30 column (Amersham Biosciences). The $\left[{ }^{3} \mathrm{H}\right]$ and $\left[{ }^{14} \mathrm{C}\right]$ content of lymph was measured by liquid scintillation counting. Data represent 6-8 mice per genotype.

Statistics. Differences between groups were compared with 1- or 2-tailed Student's $t$ test, as appropriate, or 1-way ANOVA using GraphPad Prism software (GraphPad Software), with a $P$ value of 0.05 or less being considered statistically significant. Data are presented as means \pm SEM.

\section{Acknowledgments}

This work was supported by grants from the Canadian Institutes of Health Research (CIHR) and the Heart and Stroke Foundation of British Columbia and the Yukon (to M.R. Hayden), and the NIH (grants HL49373 to J.S. Parks and DK46900 and 
HL64272 to M.M. Hussain). L.R. Brunham and B.A. Coburn are supported by CIHR studentships and are Michael Smith Foundation for Health Research doctoral trainees. J.K. Kruit is supported by the Netherlands Heart Foundation (grant 2001B043). J.M. Timmins is supported by an NIH Cardiovascular Pathology Training grant (HL07115). M.R. Hayden is a University Killam professor and holds a Canadian Research Chair in Human Genetics. Special thanks to the staff of the Wesbrook Animal Unit for expert care of mice, to Rick Havinga (University Medical Center Groningen) for performing lymph duct cannulations, and to Deborah Gumucio (University of Michigan) for generously providing Villin-Cre transgenic mice.

Received for publication November 8, 2005, and accepted in revised form January 17, 2006.

Address correspondence to: Michael R. Hayden, Centre for Molecular Medicine and Therapeutics, 950 West 28th Avenue, Vancouver, British Columbia V5Z 4H4, Canada. Phone: (604) 875-3535; Fax: (604) 875-3819; E-mail: mrh@cmmt.ubc.ca.
1. Glomset, J.A. 1968. The plasma lecithin: cholesterol acyltransferase reaction. J. Lipid Res. 9:155-167.

2. Glomset, J.A., and Norum, K.R. 1973. The metabolic role of lecithin: cholesterol acyltransferase. Perspectives from pathology. Adv. Lipid Res. 11:1-65.

3. Linsel-Nitschke, P., and Tall, A.R. 2005. HDL as a target in the treatment of atherosclerotic cardiovascular disease. Nat. Rev. Drug Discov. 4:193-205.

4. Francis, G.A., Knopp, R.H., and Oram, J.F. 1995 Defective removal of cellular cholesterol and phospholipids by apolipoprotein A-I in Tangier disease. J. Clin. Invest. 96:78-87.

5. Schmitz, G., and Langmann, T. 2001. Structure, function and regulation of the $\mathrm{ABC} 1$ gene product. Curr. Opin. Lipidol. 12:129-140.

6. Brooks-Wilson, A., et al. 1999. Mutations in ABC1 in Tangier disease and familial high-density lipoprotein deficiency. Nat. Genet. 22:336-345.

7. Rust, S., et al. 1999. Tangier disease is caused by mutations in the gene encoding ATP-binding cassette transporter 1. Nat. Genet. 22:352-355.

8. Bodzioch, M., et al. 1999. The gene encoding ATPbinding cassette transporter 1 is mutated in Tangier disease. Nat. Genet. 22:347-351.

9. Schaefer, E.J., Zech, L.A., Schwartz, D.E., and Brewer, H.B., Jr. 1980. Coronary heart disease prevalence and other clinical features in familial high-density lipoprotein deficiency (Tangier disease). Ann. Intern. Med. 93:261-266.

10. Clee, S.M., et al. 2000. Age and residual cholesterol efflux affect HDL cholesterol levels and coronary artery disease in ABCA1 heterozygotes. J. Clin. Invest. 106:1263-1270.

11. van Dam, M.J., et al. 2002. Association between increased arterial-wall thickness and impairment in ABCA1-driven cholesterol efflux: an observational study. Lancet. 359:37-42.

12. Wellington, C.L., et al. 2002. ABCA1 mRNA and protein distribution patterns predict multiple different roles and levels of regulation. Lab. Invest. 82:273-283

13. Langmann, T., et al. 1999. Molecular cloning of the human ATP-binding cassette transporter 1(hABC1): evidence for sterol-dependent regulation in macrophages. Biochem. Biophys. Res. Commun. 257:29-33.

14. Wellington, C.L., et al. 2003. Alterations of plasma lipids in mice via adenoviral-mediated hepatic overexpression of human ABCA1. J. Lipid Res. 44:1470-1480.

15. Basso, F., et al. 2003. Role of the hepatic ABCA1 transporter in modulating intrahepatic cholesterol and plasma HDL cholesterol concentrations. J. Lipid Res. 44:296-302.

16. Timmins, J.M., et al. 2005. Targeted inactivation of hepatic Abcal causes profound hypoalphalipoproteinemia and kidney hypercatabolism of apoA-I. J. Clin. Invest. 115:1333-1342. doi:10.1172/ JCI200523915.

17. Ragozin, S., et al. 2005. Knockdown of hepatic ABCA 1 by RNA interference decreases plasma HDL cholesterol levels and influences postprandial lipemia in mice. Arterioscler. Thromb. Vasc. Biol. 25:1433-1438.
18. Wu, A.L., and Windmueller, H.G. 1979. Relative contributions by liver and intestine to individual plasma apolipoproteins in the rat. J. Biol. Chem. 254:7316-7322.

19. Turley, S.D., and Dietschy, J.M. 2003. Sterol absorption by the small intestine. Curr. Opin. Lipidol. 14:233-240.

20. Stange, E.F., and Dietschy, J.M. 1983. Cholesterol synthesis and low density lipoprotein uptake are regulated independently in rat small intestinal epithelium. Proc. Natl. Acad. Sci. U. S. A. 80:5739-5743.

21. Berge, K.E., et al. 2000. Accumulation of dietary cholesterol in sitosterolemia caused by mutations in adjacent ABC transporters. Science. 290:1771-1775.

22. Wang, D.Q., and Carey, M.C. 2003. Measurement of intestinal cholesterol absorption by plasma and fecal dual-isotope ratio, mass balance, and lymph fistula methods in the mouse: an analysis of direct versus indirect methodologies. J. Lipid Res. 44:1042-1059.

23. Farrell, J.J. 2002. Digestion and absorption of nutrients and vitamins. In Sleisenger and Fordtran's gastrointestinal and liver disease. M. Feldman, L. Friedman, and M. Sleisenger, editors. Saunders. Philadelphia, Pennsylvania, USA. 1715-1750.

24. Roheim, P.S., Gidez, L.I., and Eder, H.A. 1966. Extrahepatic synthesis of lipoproteins of plasma and chyle: role of the intestine. J. Clin. Invest. 45:297-300.

25. Green, P.H., Tall, A.R., and Glickman, R.M. 1978. Rat intestine secretes discoid high density lipoprotein. J. Clin. Invest. 61:528-534.

26. Forester, G.P., Tall, A.R., Bisgaier, C.L., and Glickman, R.M. 1983. Rat intestine secretes spherical high density lipoproteins. J. Biol. Chem. 258:5938-5943.

27. Tall, A.R., and Small, D.M. 1980. Body cholesterol removal: role of plasma high-density lipoproteins. Adv. Lipid Res. 17:1-51.

28. Bearnot, H.R., Glickman, R.M., Weinberg, L., Green, P.H., and Tall, A.R. 1982. Effect of biliary diversion on rat mesenteric lymph apolipoprotein-I and high density lipoprotein. J. Clin. Invest. 69:210-217.

29. Iqbal, J., Anwar, K., and Hussain, M.M. 2003. Multiple, independently regulated pathways of cholesterol transport across the intestinal epithelial cells. J. Biol. Chem. 278:31610-31620.

30. Iqbal, J., and Hussain, M.M. 2005. Evidence for multiple complementary pathways for efficient cholesterol absorption in mice. J. Lipid Res. 46:1491-1501.

31. Hussain, M.M., Fatma, S., Pan, X., and Iqbal, J. 2005. Intestinal lipoprotein assembly. Curr. Opin. Lipidol. 16:281-285.

32. Oliveira, H.C., Nilausen, K., Meinertz, H., and Quintao, E.C. 1993. Cholesteryl esters in lymph chylomicrons: contribution from high density lipoprotein transferred from plasma into intestinal lymph. J. Lipid Res. 34:1729-1736.

33. Sipahi, A.M., et al. 1989. Contribution of plasma protein and lipoproteins to intestinal lymph: comparison of long-chain with medium-chain triglyceride duodenal infusion. Lymphology. 22:13-19.

34. Vasconcelos, K.S., et al. 1989. Origin of intestinal lymph cholesterol in rats: contribution from luminal absorption, mucosal synthesis and filtration from plasma. Lymphology. 22:4-12.

35. Quintao, E.C., et al. 1979. Origin of cholesterol transported in intestinal lymph: studies in patients with filarial chyluria. J. Lipid Res. 20:941-945.

36. Imaizumi, K., Havel, R.J., Fainaru, M., and Vigne, J.L. 1978. Origin and transport of the A-I and argininerich apolipoproteins in mesenteric lymph of rats. J. Lipid Res. 19:1038-1046.

37. Madison, B.B., et al. 2002. Cis elements of the villin gene control expression in restricted domains of the vertical (crypt) and horizontal (duodenum, cecum) axes of the intestine. J. Biol. Chem. 277:33275-33283.

38. Neufeld, E.B., et al. 2001. Cellular localization and trafficking of the human ABCA1 transporter. J. Biol. Chem. 276:27584-27590.

39. Orso, E., et al. 2000. Transport of lipids from golgi to plasma membrane is defective in Tangier disease patients and ABC1-deficient mice. Nat. Genet. 24:192-196.

40. Assmann, G., von Eckardstein, A., and Brewer, H.B. 1995. Familial high density lipoprotein deficiency: Tangier disease. In The metabolic and molecular bases of inherited disease. C.R. Scriver, A.L. Beaudet, W.S. Sly, and D. Valle, editors. McGraw Hill Inc. New York, New York, USA. 2053-2072.

41. McNeish, J., et al. 2000. High density lipoprotein deficiency and foam cell accumulation in mice with targeted disruption of ATP-binding cassette transporter-1. Proc. Natl. Acad. Sci. U. S. A. 97:4245-4250.

42. Mulligan, J.D., et al. 2003. ABCA1 is essential for efficient basolateral cholesterol efflux during the absorption of dietary cholesterol in chickens. J. Biol. Chem. 278:13356-13366.

43. Repa, J.J., and Mangelsdorf, D.J. 2002. The liver X receptor gene team: potential new players in atherosclerosis. Nat. Med. 8:1243-1248.

44. Davis, H.R., Jr., et al. 2004. Niemann-Pick C1 Like 1 (NPC1L1) is the intestinal phytosterol and cholesterol transporter and a key modulator of whole-body cholesterol homeostasis. J. Biol. Chem. 279:33586-33592.

45. Altmann, S.W., et al. 2004. Niemann-Pick C1 Like 1 protein is critical for intestinal cholesterol absorption. Science. 303:1201-1204.

46. Castelli, W.P., et al. 1986. Incidence of coronary heart disease and lipoprotein cholesterol levels. JAMA. 256:2835-2838.

47. Christiansen-Weber, T.A., et al. 2000. Functional loss of ABCA1 in mice causes severe placental malformation, aberrant lipid distribution, and kidney glomerulonephritis as well as high-density lipoprotein cholesterol deficiency. Am. J. Pathol. 157:1017-1029.

48. Glickman, R.M., and Green, P.H. 1977. The intestine as a source of apolipoprotein A1. Proc. Natl. Acad. Sci. U. S. A. 74:2569-2573.

49. Singaraja, R.R., et al. 2001. Human ABCA1 BAC transgenic mice show increased high density lipoprotein cholesterol and ApoAI-dependent efflux stimulated by an internal promoter containing liver $\mathrm{X}$ receptor response elements in intron 1 . 
J. Biol. Chem. 276:33969-33979.

50. Vaisman, B.L., et al. 2001. ABCA1 overexpression leads to hyperalphalipoproteinemia and increased biliary cholesterol excretion in transgenic mice. J. Clin. Invest. 108:303-309. doi:10.1172/ JCI200112517.

51. Singaraja, R.R., et al. 2002. Increased ABCA1 activity protects against atherosclerosis. J. Clin. Invest. 110:35-42. doi:10.1172/JCI200215748.

52. Drobnik, W., et al. 2001. ATP-binding cassette transporter A1 (ABCA1) affects total body sterol metabolism. Gastroenterology. 120:1203-1211.

53. Temel, R.E., et al. 2005. Intestinal cholesterol absorption is substantially reduced in mice deficient in both ABCA1 and ACAT2. J. Lipid Res. 46:2423-2431.

54. Groen, A.K., Oude Elferink, R.P., Verkade, H.J., and Kuipers, F. 2004. The ins and outs of reverse cholesterol transport. Ann. Med. 36:135-145.

55. Ohama, T., et al. 2002. Dominant expression of ATP binding cassette transporter- 1 on basolateral surface of Caco-2 cells stimulated by LXR/RXR ligands. Biochem. Biophys. Res. Commun. 296:625-630.

56. Murthy, S., Born, E., Mathur, S.N., and Field, F.J. 2002. LXR/RXR activation enhances basolateral efflux of cholesterol in CaCo-2 cells. J. Lipid Res. 43:1054-1064.

57. Rodriguez-Boulan, E., and Nelson, W.J. 1989. Morphogenesis of the polarized epithelial cell phenotype. Science. 245:718-725.

58. Schwartz, C.C., et al. 1978. Multicompartmental analysis of cholesterol metabolism in man. Characterization of the hepatic bile acid and biliary cholesterol precursor sites. J. Clin. Invest. 61:408-423.

59. Fielding, C.J., and Fielding, P.E. 1995. Molecular physiology of reverse cholesterol transport. J. Lipid Res. 36:211-228.

60. Tall, A.R., and Small, D.M. 1980. Body cholesterol removal: role of plasma high-density lipoproteins. Adv. Lipid Res. 17:1-51.

61. Heinen, R.J., Herbert, P.N., and Fredrickson, D.S 1978. Properties of the plasma very low and low density lipoproteins in Tangier disease. J. Clin. Invest. 61:120-132.

62. Aiello, R.J., Brees, D., and Francone, O.L. 2003. ABCA1-deficient mice: insights into the role of monocyte lipid efflux in HDL formation and inflammation. Arterioscler. Thromb. Vasc. Biol. 23:972-980.

63. Schaefer, E.J., et al. 2001. Cholesterol and apolipoprotein B metabolism in Tangier disease. Atherosclerosis. 159:231-236.

64. Breslow, J.L. 1995. Familial disorders of high-density lipoprotein metabolism. In The metabolic and molecular bases of inherited disease. C.R. Scriver, A.L. Beaudet, W.S. Sly, and D. Valle, editors. McGraw Hill Inc. New York, New York, USA. 2031-2052.

65. Peters, J.M., et al. 1997. Alterations in lipoprotein metabolism in peroxisome proliferator-activated receptor alpha-deficient mice. J. Biol. Chem. 272:27307-27312.

66. Rudel, L.L., Kelley, K., Sawyer, J.K., Shah, R., and Wilson, M.D. 1998. Dietary monounsaturated fatty acids promote aortic atherosclerosis in LDL receptor-null, human ApoB100-overexpressing transgenic mice. Arterioscler. Thromb. Vasc. Biol. 18:1818-1827.

67. Bradford, M.M. 1976. A rapid and sensitive method for the quantitation of microgram quantities of protein utilizing the principle of protein-dye binding. Anal. Biochem. 72:248-254.

68. Tso, P., Karlstad, M.D., Bistrian, B.R., and DeMichele, S.J. 1995. Intestinal digestion, absorption, and transport of structured triglycerides and cholesterol in rats. Am. J. Physiol. 268:G568-G577. 